\title{
SM Otolaryngology Associated Factors of Unilateral Sensorineural Hearing Loss among Sudanese Patients
}

\author{
Mahmoud Abdelbagi Mahmoud Taha ${ }^{1}$, Sharfi Abdelgadir Omer Ahmed ${ }^{2 \star}$ and \\ Muna Ahmed Abdulrahim ${ }^{3}$ \\ ${ }^{1}$ Assistant Professor at Faculty of Medicine, Omdurman Islamic University, Sudan \\ ${ }^{2}$ Associated Professor, Faculty of Medicine, Omdurman Islamic University, Sudan \\ ${ }^{3}$ Assistant Professor, Faculty of Medicine, Elnielin University, Consultant Otolaryngologist, Sudan
}

\section{Article Information \\ Received date: May 22, 2017 \\ Accepted date: Jun 15, 2017 \\ Published date: Jun 19, 2017 \\ *Corresponding author \\ Sharfi Abdelgadir Omer Ahmed, Associated Professor, Faculty of Medicine, Omdurman Islamic University, Amarat Khartoum, Sudan, \\ Email: doctorsharfi@gmail.com \\ Distributed under Creative Commons CC-BY 4.0}

Keywords Unilateral; Sensorineural; Hearing loss

Article DOI 10.36876/smotol.1006

\section{OPEN ACCESS} ISSN: 2574-2418

\section{Abstract}

Background: Hearing loss is a leading cause of disability worldwide and it is a significant public health problem.

Objectives: To determine the associated factors of unilateral sensorineural hearing loss among different age groups in Sudanese patients.

Methods: 115 Sudanese patients presented to Khartoum state ENT hospitals complaining of unilateral hearing loss were included.

Results: In this study 115 patients were included. Male to female ratio 1:1.3, 49 patients $(42.6 \%)$ were from Khartoum state and the rest were from different areas in Sudan. The most frequent age group was from 1-15 years representing $(38.3 \%)$ with a mean age of $24.48 \pm 1.5$. The commonest associated factor in this study was mumps and it was found in 47 of patients $(40.9 \%)$, tinnitus was the commonest presenting symptoms in unilateral Sensorineural hearing loss 81 patients $(70.4 \%)$ were assessed audiologically with pure tone audiometry and 34 patients $(59.1 \%)$ assessed by Auditory Brain Stem Response (ABR).

Conclusion: Unilateral Sensorineural hearing loss commonly presents during school-age. Mumps is the most common associated factor. Pure tone audiometry and auditory brain stem response are suitable method for the assessment and the diagnosis.

\section{Introduction}

Hearing Loss (HL) is a leading cause of disability worldwide and it is a significant public health problem in Sub-Saharan Africa and other developing countries. From 278 million people with HL worldwide, more than two thirds of them live in developing countries in whom, over 180,000 babies have a significant hearing loss are born annually $[1,2]$. Unilateral sensorineural hearing loss is defined as average pure-tone air conduction thresholds $(0.5,1,2,4 \mathrm{kHz}) \geq 30 \mathrm{~dB}$ in the impaired ear with an average air-bone gap no greater than $10 \mathrm{~dB}$ at the same frequencies and normal hearing $(\leq 15 \mathrm{~dB}$ from 0.5 to $4 \mathrm{kHz}$ ) in the good ear [3]. There are a wide variety of causes of unilateral sensorineural hearing loss; it may result from either endogenous or exogenous causes and are significantly more frequent among men than women [4]. Sensorineural hearing loss may be congenital or acquired [5]. Mumps is thought to be the most common cause of unilateral acquired sensorineural hearing loss in children and it is usually sudden in onset.

Unal et al. found that mumps accounts for approximately $2 \%$ of childhood hearing loss; $80 \%$ to $95 \%$ of these cases are unilateral sensorineural hearing loss [6]. Roizen prospectively followed 58 premature ( $\leq 32$ weeks) infants until 5 years of age. They found approximately $5 \%$ of these infants had permanent unilateral sensorineural hearing loss [7]. Baldwin et al. mentioned that bacterial meningitis may lead to bilateral or unilateral sensorineural hearing loss and was the cause of unilateral hearing impairment in $7 \%$ of their patients [8]. Niskar et al. found approximately $10 \%$ of all children in the United States have noise induce hearing loss; approximately $20 \%$ of them are unilateral sensorineural hearing loss [9].

\section{Patients and Methods}

\section{Type of study}

It is a prospective hospital based descriptive study. Study conducted between January 2014 and December 2015. Study was done in 115 Sudanese patients in Khartoum state ENT hospitals, Sudan.

\section{Inclusion criteria}




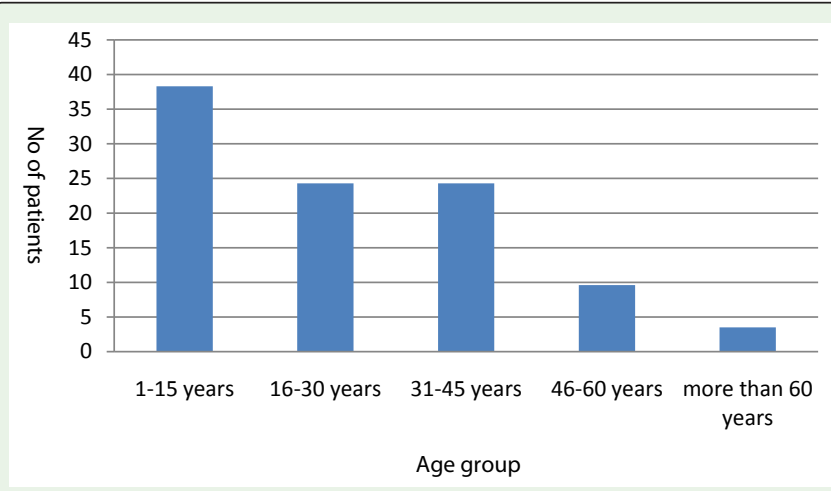

Figure 1: Age distribution among patients with unilateral hearing loss

Both males and females of all age groups with unilateral sensorineural hearing loss proved by investigations.

\section{Exclusion criteria}

Patient with conductive hearing loss or mixed hearing loss.

\section{Data collection}

Data was collected using a well-constructed questionnaire to fulfill the require data.

\section{Study tools}

Otoscopes, Tunning fork $(512 \mathrm{~Hz})$, Pure tone audiometry, tympanometry and auditory brain stem response.

\section{Ethical consideration}

Informed written consent was obtained from patients enrolled in the study.

\section{Statistical analysis}

A paragraph describing how statistics were done and comparing what variables.

\section{Results}

The total number of patients involved in this study was 115 patients. General ear, nose and throat examination was negative in all cases. All these patients were seen in Khartoum state ENT hospitals. $49(42.6 \%)$ were male while $66(57.4 \%)$ were female, and the male: female ratio was 1: 1.3. Patients' ages ranged from 1 year to 79 years,

Table 1: The associated factors of unilateral sensorineural hearing loss.

\begin{tabular}{|l|c|c|}
\hline \multicolumn{1}{|c|}{ Associated factor } & Frequency & Percentage \\
\hline Mumps & 47 & 40.9 \\
\hline Meniere's disease & 39 & 33.9 \\
\hline Congenital & 17 & 14.8 \\
\hline Head trauma & 6 & 5.2 \\
\hline Premature birth & 4 & 3.5 \\
\hline Vascular "sudden SNHL" & 1 & 0.9 \\
\hline Cerebellopontine angle tumor & 1 & 0.9 \\
\hline Total & 115 & 100 \\
\hline
\end{tabular}

Table 2: The degree of hearing loss among the studied group.

\begin{tabular}{|l|c|c|}
\hline \multicolumn{1}{|c|}{ Degree of hearing loss } & Frequency & Percentage \\
\hline Mild & 4 & 3.5 \\
\hline Moderate & 52 & 45.2 \\
\hline Severely moderate & 8 & 7.0 \\
\hline Severe & 6 & 5.2 \\
\hline Profound & 45 & 39.1 \\
\hline Total & 115 & 100 \\
\hline
\end{tabular}

with a mean age of $24.48 \pm 1.5$. The common age groups affected were from 1-15 year; 44 patients (38.3\%), 28 patients (24.3\%) from 16-30 year, 28 patients $(24.3 \%)$ from $31-45$ year, 11 patients $(9.6 \%)$ from 46 60 , and 4 patients (3.5\%) were more than 60 (Figure 1).

The commonest associated factor in this study were Mumps and it was found in 47 of patients ( $40.9 \%$ ) followed by Meniere's disease in 39 (33.9\%), congenital factors in $17(14.8 \%)$, head trauma in $6(5.2 \%)$ and premature birth in 4 (3.5\%). Other causes were vascular "sudden Sensorineural Hearing Loss" 1 (0.9\%), cerebellopontine angle tumors $1(0.9 \%)$, (Table 1$)$. Regarding the degree of hearing loss, $4(3.5 \%)$ were presented with mild hearing loss, $52(45.2 \%)$ with moderate, 8 (7\%) with severely moderate, $6(5.2 \%)$ with severe and 45 patients (39.1\%) presented with profound hearing loss (Table 2).

Clinically, there were some associated symptoms like Tinnitus which was found in 51 of patients (44.3\%) and Vertigo was found in 49 of patients (42.6\%) (Table 3 ).

Regarding the methods of assessment 81 patients (70.4\%) were assessed audiologically with pure tone audiometry and 34 patients (29.6\%) assessed by auditory brain stem response (Figure 2). In relationship between the age groups and commonest associated factors, Mumps were common in (1-15) age group, were Meniere's disease was common in (16-30) age group, Premature birth manifest only at (1-15) age group, both congenital factors and head trauma were found in different age groups. At last cerebellopontine angle tumors found only in more than 60 age group and sudden Sensorineural Hearing Loss on (31-45) age group, shown in Table 4 with a significant $P$ value (0.001).

Table 3: Symptoms of the patients $(\mathrm{No}=115)$.

\begin{tabular}{|c|c|c|}
\hline Symptom & Frequency & Percentage \\
\hline Tinnitus & 51 & 44.3 \\
\hline Vertigo & 49 & 42.6 \\
\hline
\end{tabular}

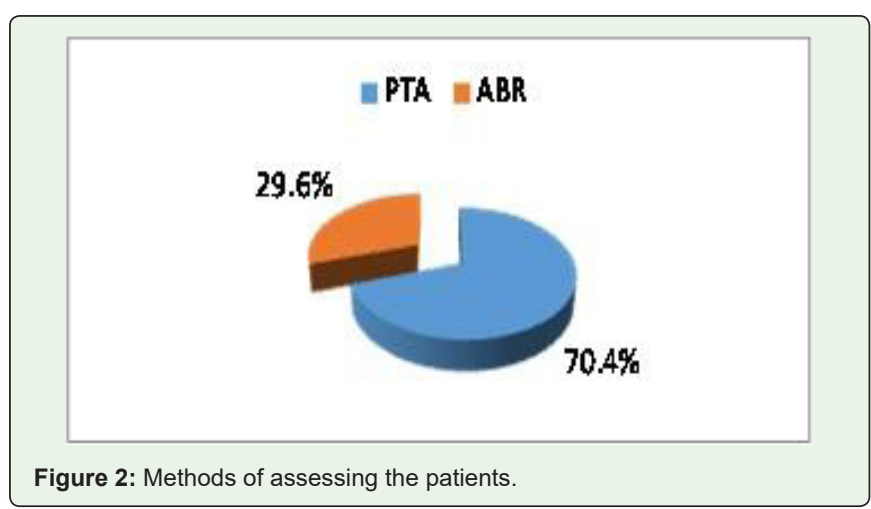


Table 4: Relationship between the age groups and the associated factors.

\begin{tabular}{|c|c|c|c|c|c|c|c|c|}
\hline \multirow[b]{2}{*}{ Age group } & \multicolumn{7}{|c|}{ Associated factors } & \multirow[b]{2}{*}{ Total } \\
\hline & Mumps & $\begin{array}{l}\text { Meniere's } \\
\text { disease }\end{array}$ & Congenital & Premature birth & $\begin{array}{l}\text { Head } \\
\text { trauma }\end{array}$ & $\begin{array}{l}\text { Sudden } \\
\text { SNHL }\end{array}$ & $\begin{array}{c}\text { Cerebellopontine angle } \\
\text { tumor }\end{array}$ & \\
\hline $1-15$ years & 31 & 3 & 5 & 4 & 1 & 0 & 0 & 44 \\
\hline $16-30$ years & 1 & 24 & 3 & 0 & 0 & 0 & 0 & 28 \\
\hline $31-45$ years & 11 & 9 & 7 & 0 & 0 & 1 & 0 & 28 \\
\hline $46-60$ years & 4 & 2 & 2 & 0 & 3 & 0 & 0 & 11 \\
\hline More than 60 years & 0 & 1 & 0 & 0 & 2 & 0 & 1 & 4 \\
\hline Total years & 47 & 39 & 17 & 4 & 6 & 1 & 1 & 115 \\
\hline
\end{tabular}

$P$ value $=0.001<0.05$ significant relationship, using chi square test

Table 5: Relationship between the associated factors and the degree of hearing loss.

\begin{tabular}{|l|c|c|c|c|c|c|}
\hline \multirow{2}{*}{$\begin{array}{c}\text { Associated } \\
\text { factor }\end{array}$} & \multicolumn{5}{|c|}{ Degree of hearing loss } & \multirow{2}{*}{ Total } \\
\cline { 2 - 7 } & Mild & Moderate & $\begin{array}{c}\text { Severely } \\
\text { moderate }\end{array}$ & Severe & Profound & \\
\hline Mumps & 0 & 11 & 4 & 1 & 31 & 47 \\
\hline Meniere's disease & 4 & 32 & 0 & 3 & 0 & 39 \\
\hline Congenital & 0 & 8 & 4 & 0 & 5 & 17 \\
\hline Premature birth & 0 & 0 & 0 & 0 & 4 & 4 \\
\hline Head trauma & 0 & 1 & 0 & 1 & 4 & 6 \\
\hline Sudden SNHL & 0 & 0 & 0 & 1 & 0 & 1 \\
\hline $\begin{array}{l}\text { Cerebellopontine } \\
\text { angle tumor }\end{array}$ & 0 & 0 & 0 & 0 & 1 & 1 \\
\hline Total & 4 & 52 & 8 & 6 & 45 & 115 \\
\hline
\end{tabular}

$P$ value $=0.001<0.05$ significant relationship, using chi square test

Table 5 show relationship between the associated factors and degree of hearing loss, in which mumps commonly causes profound Sensorineural Hearing Loss (SNHL), both of Meniere's and congenital factors found to cause moderate SNHL. Profound SNHL also found in premature birth, head trauma, sudden SNHL and cerebellopontine angle tumors, with a significant $P$ value (0.001).

\section{Discussion}

The protocol for the evaluation of a unilateral SNHL is confirmed audiometrically. The audiometric evaluation consists of a repeat pure tone audiometry with the special attention to masking. Auditory brain stem response test is also included.

Auditory Brain Stem Response (ABR) test was not carried out routinely on patients with profound hearing loss because the results would be equivocal and of a little diagnostic benefit.

Auditory brain stem response used when considered necessary e.g. below the age of 3 years, uncooperative child and frequencies above $2000 \mathrm{~Hz}$ beginning in the neonatal period.

Among five age groups included in this study, the mean age of affected patients was 24.48 years and the most frequent age group was from 1-15 years represented (38.3\%). All of Tarkkanen and Aho [10], Marttila [11] and Vartiainen [12] reported the same that is unilateral SNHL is most frequent found in school aged children.

Female were more affected than male with a male to female ratio of 1:1.3, this was compatible with Bess and Tharpe et al. who reported females predominance over males [13]. In contrast to what Everberg mentioned about male predominance [14], that is to say we couldn't find the reason for this gender difference.

Mumps was the commonest associated factor in this study, and this is compatible to Unal et al. [15] and Everberg [14] who delineates Mumps as the commonest associated factor of unilateral SNHL. This is in contrast to all of Marschalc [16] and Kinney [17] which explained other inflammatory factors like measles and meningitis are the commonest associated factors of unilateral SNHL.

In this study, hundred fifteen of the patients (100\%) presented with unilateral sensorineural hearing loss. One hundred patients (86.4\%) presented with tinnitus and vertigo. The same percentage of tinnitus was reported by Axelsson [18] and the same percentage of vertigo was reported by Bisdorff [19].

In this study clinical assessment of patients presented with unilateral sensorineural hearing loss revealed that; right ear was most frequently affected, and this is similar observation that is reported by Bess and Tharpe [13]. In contrast to what Everberg [14] reported that left ear is commonly affected, that is to say we couldn't find the reason for the affected side difference.

Majority of the patients presented with moderate degree of hearing loss $52(45.2 \%)$ followed by profound HL. This is similar observation reported by Everberg [14] due to the commonest associated factor: Mumps.

Eighty one patients (70.4\%) were assessed audiologically with pure tone audiometry and 34 patients $(59.1 \%)$ assessed by auditory brain stem response and they were also the suitable method of assessment applied by all of Kumar [20], Tos and Thompson [21] and Roizen [7]. Noder and kinney [17] do not recommend auditory brain stem response for assessment of cerebellopontine angle tumor with severe hearing loss due to abnormal results on the contralateral ear.

The single reported case of cerebellopontine angle tumor was a case report in Omdurman Military Hospital, Neurosurgery department, referred to ENT department. She was an old lady of 66 years old, presented with left ear decrease hearing, tinnitus and vertigo for 7 years. Diagnosis confirmed by MRI cerebellopontine angle, pure tone audiometry showed left moderate SNHL.

The 6 reported cases developed unilateral SNHL after sustaining head trauma. Most of them (4 cases) developed profound unilateral SNHL. Diagnosis confirmed especially on these cases by radiological investigation using high resolution $\mathrm{CT}$ scan temporal bone which showed transverse fracture. Majority of them assessed by auditory brain stem response (4cases) and the rest were assessed bypure tone audiometry. 
The author reported a case of sudden SNHL, who was an old man of 75 years old, known by hypertensive and atherosclerotic for 20 years, on regular medications and follow up, he had a history of transient ischemic attack after that he immediately developed unilateral SNHL, pure tone audiometry revealed left profound SNHL, this is similar to Oh et al. [22] who explained stronger association with pre-existing conditions of hypertension and atherosclerosis for sudden SNHL.

\section{Conclusion}

Unilateral sensorineural hearing loss affects all age's group of patients from and commonly occurring in children between 1-15 years in female gender. The common associated factor in this study was Mumps followed by Meniere's disease. The common associated symptoms with unilateral sensorineural hearing loss were tinnitus and vertigo. Pure tone audiometry and auditory brain stem response are suitable method for assessment and diagnosis.

\section{References}

1. Olusanya BO, Mars M. Hearing health-care delivery in sub-Saharan Africa-a role for tele-audiology. J Telemed Telecare. 2010; 16: 53-56.

2. Offei YN. Educational audiology in Ghana-developing screening tools fo hearing in infants and children. Doctoral dissertation, Universitätzu Köln.

3. Smith RJ, Bale JF, White KR. Sensorineural hearing loss in children. The Lancet. 2005; 365: 879-890.

4. Reiss NM, Reiss G. Differential diagnosis of unilateral hearing loss. Praxis. 2000; 89:241-247.

5. McPherson B, Swart SM. Childhood hearing loss in sub- Saharan Africa: a review and recommendations. Int J Pediatr Otorhinolaryngol. 1997; 40: 1-18.

6. Holmes SJ. Mumps. In: Viral Infections of Humans. Springer. 1997; 531-550.

7. Roizen NJ. Etiology of hearing loss in children: nongenetic causes. Pediatr Clin North Am. 1999; 46: 49-64.

8. Baldwin RL, Sweitzer RS, Freind DB. Meningitis and sensorineural hearing loss. The Laryngoscope. 1985; 95: 802-805.
9. Niskar AS, Kieszak SM, Holmes AE, Esteban E, Rubin C, Brody DJ. Estimated prevalence of noise-induced hearing threshold shifts among children 6 to 19 years of age: the Third National Health and Nutrition Examination Survey, 1988-1994, United States. Pediatrics. 2001; 108: 40-43.

10. Tarkkanen J, Aho J. Unilateral deafness in children. Acta Otolaryngol.1966 61: $270-278$.

11. Marttila TI. Results of audiometrical screening in Finnish school children. Int J Pediatr Otorhinolaryngol. 1986; 11: 39-46.

12. Vartiainen E, Karjalainen S. Prevalence and etiology of unilatera sensorineural hearing impairment in a Finnish childhood population. Int J Pediatr Otorhinolaryngol. 1998; 43: 253-259.

13. Bess FH, Tharpe AM. An introduction to unilateral sensorineural hearing loss in children. Ear Hear. 1986; 7: 3-13.

14. Everberg BG. Deafness following mumps. Acta Otolaryngol. 1957; 48: 397 403

15. Unal M, Katircioglu S, Karatay MC, Suoglu Y, Erdamar B, Aslan I. Sudden total bilateral hearing loss due to asymptomatic mumps infection. Int J Pediatr Otorhinolaryngol. 1998; 45: 167-169.

16. Marschak M. Die Blutverschiebungenbeim Menschen beihoher Umgebungs temperatur. Research in Experimental Medicine. 1931; 77: 133-143.

17. Kinney CE. Hearing impairments in children. The Laryngoscope. 1953; 63 220-226.

18. Axelsson A, Ringdahl A. Tinnitus-a study of its prevalence and characteristics. Br J Audiol. 1989; 23: 53-62.

19. Bisdorff A. Épidémiologie du vertige, de l'étourdissement et de l'instabilité, ainsiqueleurs relations avec la migraine, le mal des transports, l'anxiétédépression, le malaise vagal etl'agoraphobie. Doctoral dissertation, Université de Lorraine.

20. Kumar A, Maudelonde C, Mafee M. Unilateral sensorineural hearing loss: analysis of 200 consecutive cases. The Laryngoscope. 1986; 96: 14-18.

21. Tos MI, Thomsen J. Epidemiology of acoustic neuromas. J Laryngol Otol. 1984; 98: 685-692

22. Oh JH, Park K, Lee SJ, Shin YR, Choung YH. Bilateral versus unilateral sudden sensorineural hearing loss. Otolaryngol Head Neck Surg. 2007; 136: 87-91. 